\title{
Assessment of COPD wellness tools for use in primary care: an IPCRG initiative
}

This article was published in the following Dove Press journal:

International Journal of COPD

16 July 2012

Number of times this article has been viewed

\author{
Andrew J Cave' \\ Lana Atkinson' \\ Ioanna G Tsiligianni ${ }^{2,3}$ \\ Alan G Kaplan ${ }^{4}$ \\ 'Department of Family Medicine, \\ University of Alberta, Edmonton, \\ Canada; ${ }^{2}$ Department of General \\ Practice, University Medical Centre \\ of Groningen, Groningen, Netherlands; \\ ${ }^{3}$ Agia Barbara Health Care Centre, \\ Heraklion, Greece; ${ }^{4}$ Family Physician \\ Airways Group of Canada, North \\ York, Canada
}

\begin{abstract}
COPD is considered a complex disease and global problem that is predicted to be the third most common cause of death by 2030 . While managing this chronic condition, primary health care practitioners are faced with the ongoing challenge of achieving good quality of life and overall "wellness" for those affected. As such, a practical tool for monitoring quality of life in a clinical setting is required. However, due to the wide variety of general and disease-specific tools from which to choose, primary health care practitioners are given minimal guidance as to which tool may be most appropriate. To address these challenges, the International Primary Care Respiratory Group (IPCRG) proposed the creation of a user's guide for primary health care practitioners to assess "wellness" in COPD patients in an everyday clinical setting. This short report outlines the process by which the IPCRG Users' Guide to COPD "Wellness" Tools was developed. It also describes why this guide has the potential to be of great value in guiding primary health care practitioners to improve patient wellness.
\end{abstract}

Keywords: wellness, quality of life, primary care, instrument

\section{Introduction}

COPD is considered a complex disease that, according to the World Health Organization, is one of the most prevalent diseases worldwide and is predicted to be the third most common cause of death by $2030 .{ }^{1}$ As with other chronic diseases, one of the main goals in managing COPD is achieving a good quality of life and overall "wellness" for those affected. ${ }^{2}$ In achieving and maintaining "wellness," primary health care practitioners are faced with the challenge of choosing from appropriate tools that easily and effectively assess the severity of the disease and measure its effect on improving the patient's overall quality of life. ${ }^{3,4}$ However, primary health care practitioners must choose from a wide variety of the available general and disease-specific tools, while receiving minimal guidance as to which tool may be most appropriate. ${ }^{3}$ To address these challenges, the International Primary Care Respiratory Group (IPCRG) recently proposed the creation of a user's guide for primary health care practitioners to assess "wellness" in COPD patients in an everyday clinical setting. The IPCRG has a special focus on research, management, and education in respiratory diseases in primary care. At the request of the Research Subcommittee of the IPCRG, the Family Physicians Airways Group of Canada (FPAGC), an IPCRG member organization, accepted the task on IPCRG's behalf. This short report outlines the development process of the IPCRG Users' Guide to COPD "Wellness" Tools and describes why the guide has the potential to be of great value in guiding primary health care practitioners to improve patient wellness.
Correspondence: Andrew J Cave Department of Family Medicine, 901 College Plaza, University of Alberta, Edmonton T6G 2C8, Alberta, Canada $\mathrm{Tel}+\mathrm{I} 7804928102$

Fax +I 7804922593

Email andrew.cave@ualberta.ca 
To date, COPD has been monitored mainly by lung function parameters that only weakly reflect patient wellness. ${ }^{5,6}$ To address this concern, there have been several recent reviews of tools used to evaluate the wellness of COPD patients. ${ }^{3,7-11}$ However, the tools evaluated address specific aspects of the condition, such as breathlessness in advanced cases of respiratory diseases or the setting of treatment centers. ${ }^{10,11}$ Furthermore, some tools are broader than others in the aspects they address, which may complicate the decision-making process for primary health care practitioners when selecting appropriate tools. ${ }^{7}$

In 2005, Fitzpatrick and colleagues performed a systematic review of health-related measures for a number of common chronic diseases, including COPD. ${ }^{3}$ They divided relevant health outcome tools into two groups: (1) generic (applicable to several diseases or populations) and (2) disease-specific (measuring health in only one condition), such as for COPD. For the purpose of our project, focus was on disease-specific tools, as they "may have greater clinical appeal due to their specificity of content, and associated increased responsiveness to specific changes in condition." 3 Fitzpatrick and colleagues identified key criteria for assessing the quality of tools and selecting appropriate outcome measures, which included: validity, reliability, responsiveness, precision, acceptability, and feasibility. Using the available evidence, they provided useful guidance to primary health care practitioners to inform them of the range of tools available, relative to their setting. ${ }^{3}$ We built on and refined Fitzpatrick's criteria to create a customized guide for the selection of the best disease-specific assessment tool for managing wellness in COPD in a primary care setting.

\section{Methods}

To get a sense of the number, type, and quality of tools currently available internationally to primary health care practitioners managing patients with COPD, a comprehensive, systematic search was performed. Our search reviewed the English language literature published up to 2010.

Searches were conducted in the following databases: MEDLINE $^{\circledR}$, Embase, PubMed ${ }^{\circledR}$, PsycINFO $^{\circledR}$, CINAHL $^{\circledR}$, Health and Psychosocial Instruments, The Medical Algorithms Project, The Cochrane Library, Science Direct, and ProQuest Dissertations and Theses. This list includes databases not searched in previous reviews. ${ }^{3}$ The search of these databases combined both controlled vocabulary and keyword terms (when appropriate) relating to the following core concepts: (1) chronic obstructive pulmonary disease, (2) measurement instruments (eg, questionnaires, evaluations, assessments, tests, measurements, health status indicators, and severity of illness indices), and (3) wellness (eg, quality of life). Additional articles, subsequently identified from references cited in the included articles, were also included. Furthermore, a Google search helped identify additional resources, as well as relevant gray literature. In this case, no date or language restrictions were applied. Articles published prior to 1995, animal studies, and studies published in languages other than English were excluded.

The results from each database were imported into a RefWorks database,(Refworks version 2.0, Refworks-Cos Bethesda, USA), where duplicate articles were removed. (Further information on the detailed search strategies employed and results can be obtained from the corresponding author.) The summary of results is presented in Table 1.

A form of "rapid appraisal" was performed by two independent researchers, whereby the titles and abstracts of the selected articles were scanned and reviewed for relevance, and a list of tools that combined or discussed aspects of "COPD" and "wellness" was identified. In addition, the quality of the articles was assessed, with those that failed to meet a predetermined set of inclusion criteria culled from the database. Articles that (1) were peer-reviewed, (2) provided empirical evidence of measurement properties, and (3) were relevant to a primary care setting were included. Editorials/Commentaries and articles lacking authority and/or currency were excluded.

A logic chart was constructed to pool selected tools according to their purpose and approach. Overall, 1825 articles relating to $84 \mathrm{COPD}$-specific tools were identified. Of those 84 tools, 42 were associated with patient-related health outcomes or "wellness."

Table I Summary of results

\begin{tabular}{|c|c|c|}
\hline Database & Initial results & Final results $^{a}$ \\
\hline MEDLINE ${ }^{\circledR}$ I & 1657 & - \\
\hline MEDLINE 2 (refined search) & 385 & 377 \\
\hline Embase I & 46 & - \\
\hline \multirow[t]{2}{*}{ Embase 2 (expanded search) } & 280 & 317 (combined \\
\hline & & I and 2) \\
\hline PubMed $^{\circledR}$ & 160 & 155 \\
\hline PsycINFO & 94 & 93 \\
\hline $\mathrm{CINAHL}^{\circledR}$ & 14 & 13 \\
\hline $\mathrm{HaPI}$ & 271 & 234 \\
\hline The Medical Algorithms Project & 165 & 165 \\
\hline The Cochrane Library & 74 & 74 \\
\hline Science Direct & 328 & 317 \\
\hline ProQuest Dissertations and Theses & 80 & 80 \\
\hline Total & 3554 & 1825 \\
\hline
\end{tabular}

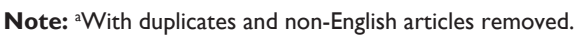

Abbreviations: CINAHL, Cumulative Index to Nursing and Allied Health Literature; HaPI, Health and Psychosocial Instruments. 
Due to the wide range of articles employing a variety of quantitative and qualitative methods, the members of the IPCRG Research Subcommittee were invited to comment on the evaluation criteria and rank their preferred tools from the health outcomes/wellness group. When evaluating and ranking the tools, they were asked to consider supporting evidence from the research literature, as well as their own clinical and research experience. Seven of the twelve subcommittee members provided feedback, with one declaring a conflict of interest.

\section{Results}

Tools that received three or more votes from the participating IPCRG Research Subcommittee members were selected for further assessment. This resulted in the identification of nine disease-specific tools that assess various aspects of "wellness": (1) Airways Questionnaire, (2) Breathing Problems Questionnaire - Short, (3) COPD Activity Rating Scale, (4) COPD Assessment Test (CAT), (5) Clinical COPD Questionnaire (CCQ), (6) Chronic Respiratory Disease Questionnaire (CRQ), (7) Medical Research Council, Dyspnoea, (8) 10 Item Respiratory Illness Questionnaire - Monitoring, and (9) St George's Respiratory Disease Questionnaire (SGRQ). ${ }^{12-23}$ Figure 1 illustrates the tool selection process.

Given the feedback provided by the IPCRG Research Subcommittee, changes were made to the original evaluation criteria derived from Fitzpatrick and colleagues. ${ }^{3}$ They were expanded to include the following six categories: (1) validity/ reliability, (2) responsiveness, (3) applicability to a primary care population, (4) practicality/ease of administration, (5) testing in practice, and (6) other language versions.

The comments and rankings from the IPCRG Research Subcommittee and the supporting evidence from the identified literature relating to each of the nine tools were used to evaluate each tool, using the six newly established and refined evaluation criteria. Once all the supporting evidence had been evaluated, it was transferred into a spreadsheet

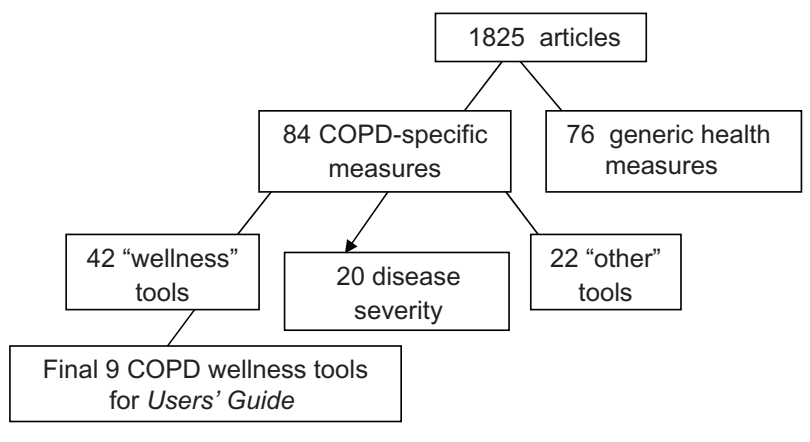

Figure I Summary of tool selection process. and distributed to the IPCRG Research Subcommittee for a second round of comments and feedback. Once reviewed and validated by the subcommittee, the supporting evidence spreadsheet was translated into an assessment grid, using a simple and effective visual ranking scale (Table 2). This visual ranking scale uses a display of five different colorcoded smiling/sad faces used to rank each of the nine tools, according to the six criteria. The five ranking possibilities include: (1) very poor, (2) not good enough (if this criterion is important), (3) good enough, (4) recommended, and (5) highly recommended. This visual ranking scale was patterned after a previously used system that successfully provided resources for asthma control tools. ${ }^{24}$ Full details for each tool, including tool description and limitations, as well as directions on where to find each tool and obtain user permission, are available in the IPCRG Users' Guide to COPD "Wellness" Tools (Appendix). ${ }^{25}$

\section{Discussion}

The variety of COPD measurement tools identified in the literature suggests that there are important differences between the tools, with no one tool meeting all requirements. ${ }^{6,10,11}$ This is largely due to each tool's inherent design and purpose. We assessed each tool from the vantage point of patient wellness during clinical care in a primary care setting. We were also mindful of the need for "appropriateness" (see Fitzpatrick et $\mathrm{al}^{3}$ ), whereby the tool is acceptable to health care practitioners and patients. ${ }^{3}$

Therefore, for a tool to rank high on our visual ranking scale, it had to be disease specific and it needed to provide satisfactory evidence relating to its psychometric qualities (criteria 1 and 2). It also had to have a proven record of successful use, if not in primary care, then at least in ambulatory care in a clinical setting (criteria 3 and 5). Furthermore, it had to be very easy to administer and interpret, as well as inexpensive (criteria 4). While our search was conducted for English-language articles, the international members of the IPCRG Research Subcommittee noted the availability of tools described in other languages as well (criteria 6).

Of the top nine tools discussed in the Users' Guide, the CCQ scored well on all criteria for suitability for use in primary care. ${ }^{17,18}$ Its main benefits are that it is easy to use and it can be completed in approximately 2 minutes by the patient. The CCQ is available in more than 52 languages (an ongoing process) and it addresses common outcomes, such as mental status. The CAT also scored well, even though it was introduced relatively recently, in 2009..$^{15,16}$ The CAT is a simple and straightforward questionnaire that addresses 
Table 2 Visual ranking scale

\begin{tabular}{llll}
\hline Very poor & $\begin{array}{l}\text { Not good enough, if this } \\
\text { criterion is important }\end{array}$ & $\begin{array}{l}\text { Good enough } \\
\text { recommended }\end{array}$ \\
\hline
\end{tabular}

a range of issues related to COPD when assisting primary health care practitioners in assessing overall patient wellbeing and quality of life. Although we lack sufficient data to assess CAT's responsiveness over time, its main benefits are that it has been designed specifically for use in the primary care clinical setting, is not time consuming, and is already available in many languages. Ongoing testing may show that it is among the most appropriate.

Two of the oldest and most widely used tools, the CRQ and the SGRQ, have been extensively used, resulting in some familiarity, especially in the clinical trial setting. ${ }^{19,20,23}$ However, despite their longevity and being ranked highly in the assessment grid, both have limitations: the CRQ has limited availability in languages other than English and the SGRQ is long and difficult to administer in primary care populations.

Very few articles addressed the issue of the "ceiling" or "basement" limitations of the tools. These terms refer to the ability of the tool to continue to measure changes in health status at the extremes of health. For example, if a patient scores a zero for health status on a tool (the basement score for that tool) but then clinically deteriorates, the tool cannot capture that deterioration. Therefore, that tool has a basement limitation. It may still be very useful in mild or moderately severe COPD patients but not in severe or very severe patients. Furthermore, the construction of most tools did not account for responsiveness to changes over time. Although we did not include it in the ranking criteria, some of the tools are not tested for use following an exacerbation and this may be important sometimes.

A weakness of our approach may be the omission, albeit by design, of generic health outcome tools, such as the Short-Form Health Survey questionnaire or the Sickness Impact Profile scale. These tools could add value, as they allow comparison with other conditions outside COPD. ${ }^{26,27}$ If health care practitioners are planning to compare wellness across a series of diseases, they might use these tools preferentially, but the scoring system makes comparisons difficult. Conversely, because these tools are general health status and quality of life instruments, their use may be of limited value for COPD, as they do not provide diseasespecific information.
As stated by Fitzpatrick and colleagues, "although there are relatively clear cut and widely agreed criteria to assess measurement properties of instruments, there are no clearcut explicit criteria for how to weigh the balance of evidence for instruments comparatively." 3 In our case, each tool was considered in detail by the IPCRG Research Subcommittee, using their practitioner/practical judgment and experience as practicing clinicians and researchers. Therefore, we believe the "consensus" approach employed by the IPCRG Research Subcommittee was a realistic alternative to formal evaluation by template.

We had a moderate response from the collaborators. One of the collaborators declared a potential conflict of interest and did not provide scores, although that individual did comment on the findings and the analysis. Others were also involved in the development of some of the highly ranked tools. Some of the articles suggest multiple variations of a tool, thus it was difficult in some articles to determine which version was being tested (eg, the Breathing Problems Questionnaire (BPQ) and its short form). ${ }^{13}$ Furthermore, the identification of tools published in languages other than English was limited, due to the margins of our initial search strategy. However, the IPCRG Research Subcommittee participants did consider that many of the articles included websites that provided supporting information on the availability of articles published in other languages (eg, the CCQ and the CAT).

One of the strengths of this review is that we performed an extensive, targeted search of more databases and resources than previous investigations with a similar objective. ${ }^{3}$ Our search also included tools that were developed after the aforementioned studies were published. ${ }^{3}$ Furthermore, we did not confine ourselves to just one aspect or symptom (eg, dyspnea), as is the case in other reviews. ${ }^{10,11}$ In this study, we addressed relevance to clinical primary care settings and focused on and refined key criteria identified by Fitzpatrick and colleagues as being critical in assessing the quality and appropriateness of these tools. ${ }^{3}$ In addition, we presented each tool in a simple way, to facilitate practitioner choice. Because most COPD cases are managed in primary care facilities, such a review of the existing tools was necessary, as was the resulting guide. Furthermore, our review of the 
existing tools may be of great use to those undertaking research in this area.

To follow up on this study, we propose that future work review tools that assess the severity of disease/clinical aspects of COPD in primary care and measure or predict associated features, such as depression and other related comorbidities. We also recommend that a repeat review be undertaken in 5-8 years, by which time some of the more recently introduced instruments (eg, the CAT) will have undergone further evaluation and results will have been formally disseminated.

\section{Conclusion}

We have identified useful, high-quality tools relevant to the IPCRG initiative to create the IPCRG Users' Guide to COPD "Wellness" Tools. ${ }^{25}$ It is our intention to provide suggestions, not recommendations, on tools. With this new, customized guide, we offer our analysis of what could be considered and how these tools perform against a set of refined criteria for use in a primary care setting. We have concentrated on "wellness," placing the patient ahead of the disease, which is increasingly becoming a desirable health outcome measure for governments and policy makers. Above all, we provide valuable assistance to primary health care practitioners in choosing the right tools for use in the management of patients with COPD.

\section{Acknowledgments}

The authors would like to thank Sian Williams and Lyn Danzig of IPCRG for their assistance with logistics and communications within the group. The authors also would like to thank the IPCRG Research Subcommittee for their participation. The study was funded by a grant from IPCRG Research Fund.

\section{Disclosure}

All authors contributed to the conceptualization and design of the study, data gathering and analysis, and manuscript preparation. They have all approved the final version. None of the authors has a conflict of interest to declare in this work.

\section{References}

1. Pauwels RA, Buist AS, Calverley PM, et al. Global strategy for the diagnosis, management, and prevention of chronic obstructive pulmonary disease. NHLBI/WHO global initiative for chronic obstructive lung disease (GOLD) workshop summary. Am J Respir Crit Care Med. 2001;163(5):1256-1276.

2. Heyworth IT, Hazell ML, Linehan MF, Frank TL. How do common chronic conditions affect health-related quality of life? Br J Gen Pract. 2009;59(568):e353-e358.
3. Fitzpatrick R, Bowling A, Gibbons E, et al. A Structured Review of Patient-Reported Measures in Relation to Selected Chronic Conditions, Perceptions of Quality of Care and Carer Impact. Oxford: Report to the Department of Health, University of Oxford; 2006. Available from: http://phi.uhce.ox.ac.uk/pdf/ChronicConditions/DH_REVIEWS_ NOVEMBER_2007.pdf. Accessed December 23, 2011.

4. Garratt A, Schmidt L, Mackintosh A, Fitzpatrick R. Quality of life measurement: bibliographic study of patient assessed health outcome measures. BMJ. 2002;324(7351):1417-1421.

5. Jones PW. Health status measurement in chronic obstructive pulmonary disease. Thorax. 2001;56(11):880-887.

6. Tsiligianni I, Kocks J, Tzanakis N, Siafakas N, van der Molen T. Factors that influence disease-specific quality of life or health status in patients with COPD: a review and meta-analysis of Pearson correlations. Prim Care Respir J. 2011;20(3):257-268.

7. Stucki A, Stucki G, Cieza A, Schuurmans MM, Kostanjsek N, Ruof J Content comparison of health-related quality of life instruments for COPD. Respir Med. 2007;101(6):1113-1122.

8. Cazzola M, MacNee W, Martinez FJ, et al. Outcomes for COPD pharmacological trials: from lung function to biomarkers. Eur Respir J. 2008;31(2):416-469.

9. Starkie H, Briggs A. Outcome Measures for the Assessment of Treatment Results in Chronic Obstructive Pulmonary Disease. Glasgow: Public Health and Health Policy, University of Glasgow; 2007.

10. Bausewein C, Farquhar M, Booth S, Gysels M, Higginson IJ. Measurement of breathlessness in advanced disease: a systematic review. Respir Med. 2007;101(3):399-410.

11. Dorman, S, Byrne A, Edwards A. Which measurement scales should we use to measure breathlessness in palliative care? A systematic review. Palliat Med. 2007;21(3):177-191.

12. Hajiro T, Nishimura K, Jones PW, et al. A novel, short, and simple questionnaire to measure health-related quality of life in patients with chronic obstructive pulmonary disease. Am J Respir Crit Care Med. 1999;159(6):1874-1878.

13. Hyland ME, Singh SJ, Sodergren SC, Morgan MP. Development of a shortened version of the Breathing Problems Questionnaire suitable for use in a pulmonary rehabilitation clinic: a purpose-specific, diseasespecific questionnaire. Qual Life Res. 1998;7(3):227-233.

14. Morimoto M, Takai K, Nakajima K, Kagawa K. Development of the chronic obstructive pulmonary disease activity rating scale: reliability, validity and factorial structure. Nurs Health Sci. 2003;5(1):23-30.

15. Jones PW, Harding G, Berry P, Wiklund I, Chen WH, Kline Leidy N. Development and first validation of the COPD Assessment Test. Eur Respir J. 2009;34(3):648-654.

16. Jones PW, Price D, van der Molen T. Role of clinical questionnaires in optimizing everyday care of chronic obstructive pulmonary disease. Int J Chron Obstruct Pulmon Dis. 2011;6:289-296.

17. Van der Molen T, Willemse BW, Schokker S, ten Hacken NH, Postma DS, Juniper EF. Development, validity and responsiveness of the Clinical COPD Questionnaire. Health Qual Life Outcomes. 2003;1:13.

18. Stallberg B, Nokela M, Ehrs PO, Hjemdal P, Jonsson EW. Validation of the Clinical COPD Questionnaire (CCQ) in primary care. Health Qual Life Outcomes. 2009;7:26.

19. Tsai CL, Hodder RV, Page JH, Cydulka RK, Rowe BH, Camargo CA Jr. The short-form chronic respiratory disease questionnaire was a valid, reliable, and responsive quality-of-life instrument in acute exacerbations of chronic obstructive pulmonary disease. J Clin Epidemiol. 2008;61(5):489-497.

20. Hajiro T, Nishimura K, Tsukino M, Ikeda A, Koyama H, Izumi T. Comparison of discriminative properties among disease-specific questionnaires for measuring health-related quality of life in patients with chronic obstructive pulmonary disease. Am J Respir Crit Care Med. 1998;157(3 Pt 1):785-790.

21. Bestall JC, Paul EA, Garrod R, Garnham R, Jones PW, Wedzicha JA. Usefulness of the Medical Research Council (MRC) dyspnoea scale as a measure of disability in patients with chronic obstructive pulmonary disease. Thorax. 1999;54(7):581-586. 
22. Jacobs JE, Maille AR, Akkermans RP, van Weel C, Grol RP. Assessing the quality of life of adults with chronic respiratory diseases in routine primary care: construction and first validation of the 10-Item Respiratory Illness Questionnaire-monitoring 10 (RIQ-MON10). Qual Life Res. 2004;13(6):1117-1127.

23. Jones PW, Quirk FH, Baveystock CM. The St George's Respiratory Questionnaire. Respir Med. 1991;85(Suppl B):25-31.

24. International Primary Care Respiratory Group (IPCRG). The IPCRG Users' Guide to Currently Available Asthma Control Tools. Westhill: IPCRG; 2009. Available from: http://www.theipcrg.org/resources/ controltablefinalversion151009.xls. Accessed December 23, 2011.
25. Cave AJ, Tsiligianni I, Chavannes N, Correia de Sousa J, Yaman H. IPCRG Users' Guide to COPD "Wellness" Tools. Westhill: IPCRG; 2010 September. Available from: http:/www.theipcrg.org/resources/ ipcrg_users_guide_to_copd_wellness_tools.pdf.Accessed December 23, 2011.

26. Ware JE Jr, Sherbourne CD. The MOS 36-item short-form health survey (SF-36). I. Conceptual framework and item selection. Med Care. 1992;30(6):473-483.

27. Bergner M, Bobbit RA, Carter WB, Gilson BS. The Sickness Impact Profile: development and final revision of a health status measure. Med Care. 1981;19(8):787-805. 


\section{Appendix \\ IPCRG users' guide to COPD "wellness" tools}

As well as being a lung disease, chronic obstructive pulmonary disease (COPD) is an illness with complications that are experienced in different ways by patients. There are over 80 tools that have been developed to measure different aspects of COPD. This users' guide reviews nine of the more than 42 tools that measure the illness or wellness experience of the patient with COPD. It includes tools that measure health status or quality of life as well as tools that measure COPD features such as dyspnoea and breathing problems.

It has been produced by the International Primary Care Respiratory Group (IPCRG) as a practical guide for healthcare professionals working in their everyday clinical practice rather than for academic research use. Another guide which is currently in preparation contains the tools for assessing the disease severity and the third guide in the series will contain tools that measure associated features such as depression in COPD.

In the "Wellness in COPD" tool table/grid (Figure A1), there are nine tools named on the left that we, as international primary care clinicians, judged likely to be most useful in routine management of our patients with COPD. Each of the vertical columns refers to a desirable criterion for choosing a wellness tool for use in primary care. How each tool performs for that criterion is shown by the "smiley face" in that square. (The key for the faces is given above the grid.)

These criteria are:

1. Validity/reliability: Does this tool have face and content validity - has it been shown to actually measure what it is designed to measure? Is it sufficiently reliable?

2. Responsive: Is it adequately responsive to changes in the patient's condition - does it indicate deterioration when the patient's condition deteriorates clinically?

3. Primary care population: Is it applicable to a primary care population that includes people with the full range of mild to very severe COPD?

4. Practical/easy to administer: Is it practical for daily clinical assessment? Does it have scores that are easy to use for reassessment in follow-up? Is it easy to use by interview or telephone? Can it be self-completed in the waiting room, by post or e-mail? Is it sufficiently economical of time to be used in daily practice?

5. Tested in Practice: Have the IPCRG authors of this review used the tools in their practice - what was their experience? Is it applicable in daily primary care clinical practice? Is it easy to complete within a routine primary care consultation?
6. Other languages: Has it been translated and validated in other languages? Is it easy for busy clinicians to find those translations in websites?

Time to complete the tools was considered extremely important, and has been taken into consideration and incorporated in criterion four.

\section{Which tool to select?}

Depending on which criterion is most important for your particular need at the time of choosing, the guide will assist your choice. We did not weight these criteria but you could do that. You are advised to read the notes at the bottom of the table before choosing your tool. With this guide our intention is to give suggestions but not recommendations on tools. The purpose is to offer the reader our analysis of what could be considered by a practising clinician, and of how the tools perform against a set of criteria.

In the notes on each of the tools provided on pages 7-10, there is information on where to obtain the tools and conditions for using them.

For further information, please see: http://www.theipcrg. org/resources/resources_copd.php.

\section{Tool description and limitations Airways questionnaire (AQ20)}

Correlates well with SGRQ and has only 20 items (yes/no). Short and easy to complete in 2 minutes. Useful in a clinical setting. Self-administered. Responds to changes, less discriminating in mild COPD. Spanish and Japanese versions available. High score indicating poor QOL.

\section{Where you can get this tool}

Professor Paul Jones, Professor of Respiratory Medicine, Head of Division of Clinical Sciences, St George's University of London. Email: pjones@sgul.ac.uk. See also: Yvonne Forde, Academic Secretary, Cardiac and Vascular Sciences, St George's University of London. Email: yforde@sgul.ac.uk.

\section{Cost/conditions of use}

Permission must be obtained from the authors.

For more information, see American Thoracic Society at: http://qol.thoracic.org/sections/instruments/ae/pages/airquest.html.

\section{Breathing problems questionnaire- short (BPQ-S)}

Short form of the BPQ. Not COPD specific. Self-administered, used in mild to moderate COPD. The BPQ-S is more discriminating for COPD than the longer form. 


\section{"Wellness in COPD" tool table/grid}

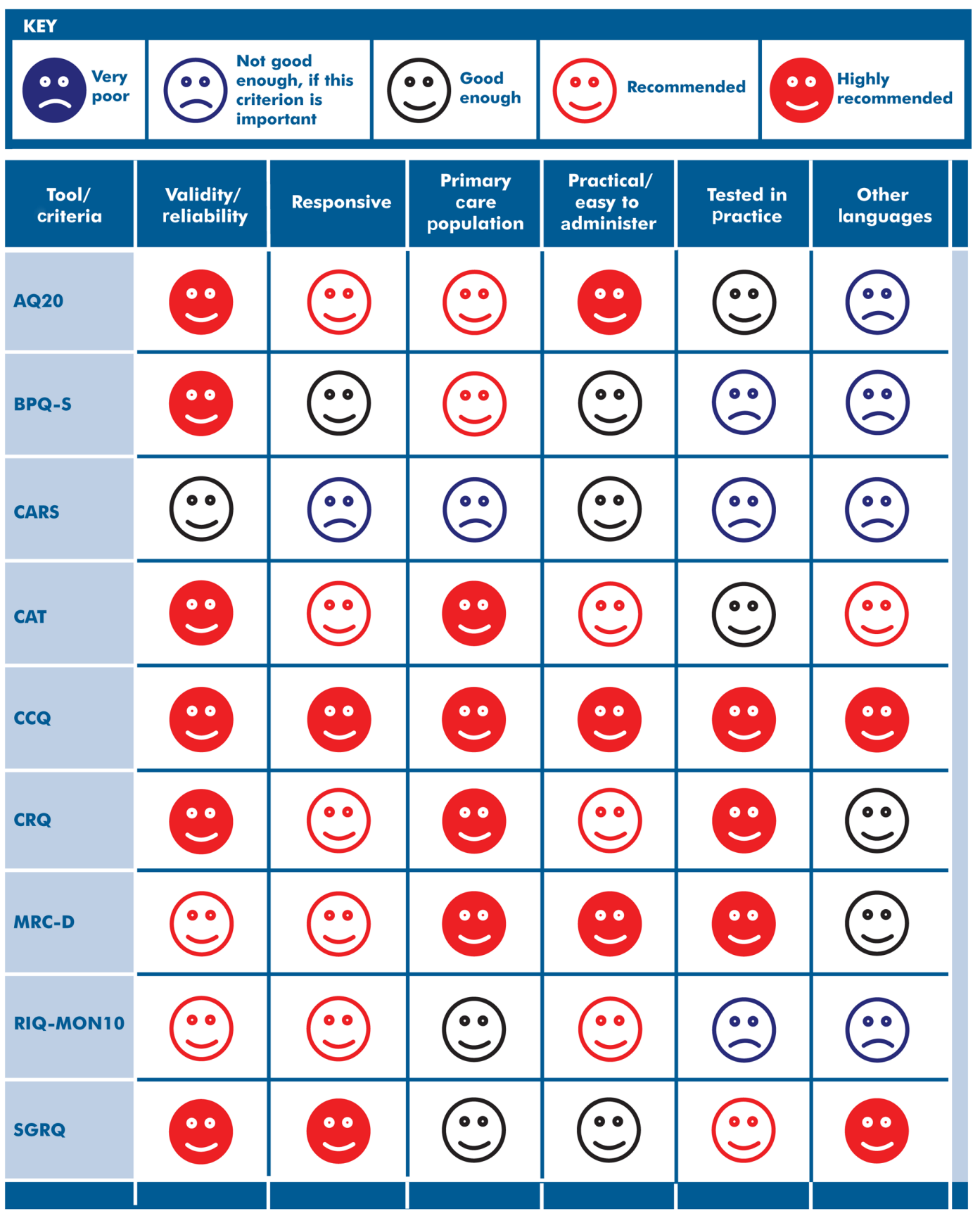

Figure AI IPCRG Users' Guide to COPD Wellness Tools. ${ }^{25}$

Notes: All of the tools reported above need no training or equipment to complete. Some questionnaires require you to request permission before you use them, and some may be subject to charges. Unless specified, please contact the authors if you wish to use any of these tools in your routine practice or for research. We have provided email addresses correct at the time of printing.

Where you can get this tool

ME Hyland at: mhyland@plymouth.ac.uk. For a direct link to the questionnaire, visit: http://www.psy.plymouth. ac.uk/research/mhyland/ or http://www.psy.plymouth.ac.uk/ research/mhyland/bpq.pdf.

\section{Cost/conditions of use}

Permission must be obtained from the authors.

\section{COPD activity rating scale (CARS)}

Measures life-related activities in COPD. Validity and reliability tested but discriminating power not tested. 4 factors (self-care, domestic activities, outdoor activities and social interaction) with 12 items. Easy three-point scale. Limited literature/studies available. Higher scores indicate less impairment. 


\section{Where you can get this tool}

Michiko Morimoto, Faculty of Health Science, Okayama University Medical School, 5-2-1 Sikata-cho Okayama-shi, Okayama700-8558, Japan.Email:mmichiko@ md.okayama-u.ac.jp.

\section{Cost/conditions of use}

Permission must be obtained from the authors.

For more information, see American Thoracic Society at: http://qol.thoracic.org/sections/instruments/ae/pages/cars. html.

\section{COPD assessment test (CAT)}

Short, simple questionnaire for monitoring long-term followup of COPD. Aimed at primary care practice. Validated in 3 international studies. 8 items, six-point scale, responds to exacerbations. Self-administered. Covers a wide range of symptoms. Not been widely used yet as only published in 2009. Available in many translations, although not all validated. Total score can be calculated on the website. Higher scores represent worse health.

\section{Where you can get this tool}

http://www.catestonline.org/.

\section{Cost/conditions of use}

Free for use by professionals and patients in daily clinical practice. It requires permission if organisations wish to use it for academic or commercial use or other professional reasons.

\section{Clinical COPD questionnaire (CCQ)}

Well validated and reliable. Responds to stopping smoking and detects mild from moderate and severe states. Measures functional and mental capacities as well as symptoms. Specific to COPD, as it measures COPD-related health status. Self-administered in daily practice. 10 items on previous week's symptoms are easy to apply. Also available in a $24 \mathrm{~h}$ version. Practical and widely used. More than 53 translations: not all are validated. Higher scores represent worse health.

\section{Where you can get this tool}

http://www.ccq.nl.

\section{Cost/conditions of use}

The use of the questionnaire in daily clinical practice is free of charge. Copyright: not to be altered, sold, translated, and used in international research without the approval of the author.

\section{Chronic respiratory disease questionnaire (CRQ)}

Well validated and reliable in testing. Responds to changes over time and long-term use as well as changes in condition after Emergency Department treatment of exacerbations. 20 items, 4 domains: Dyspnoea, fatigue, emotional function, mastery. Has been used by interviewer, telephone or self-administered. Many translations. Higher scores indicate better health-related quality of life.

\section{Where you can get this tool}

Contact for all matters relating to the CRQ is Mr Sunita Asrani: Email: asranis@mcmaster.ca.

\section{Cost/conditions of use}

Permission must be obtained from the authors.

For more information and to request permission and use: http://milo.mcmaster.ca/questionnaires/qol-request.

\section{Medical research council, dyspnoea (MRC-D)}

Widely used to assess how symptom (dyspnoea) limits activities of daily living. Well validated. Five simple items but ONLY measures dyspnoea, not other outcomes. Portuguese version validated in Brazil.

\section{Where you can get this tool}

For online access, visit: http://www.nice.org.uk/usingguid ance/commissioningguides/pulmonaryrehabilitationservice forpatientswithcopd/mrc_dyspnoea_scale.jsp. Since this is a long link, you may need to re-type it to ensure the link is not broken.

\section{Cost/conditions of use}

Information not available.

\section{I0 item respiratory illness questionnaire- monitoring (RIQ-MONIO)}

A reduced tool from the 55 item QoL RIQ tool. Wellvalidated against SF-36 and MRC scales. Sensitive to change in stable and improving mild to moderate patients. 2 factors (physical + emotional complaints and physical + social limitations) five items each. Not COPD specific. Tested in primary care.

\section{Where you can get this tool}

JE Jacobs. Radboud University Medical Centre, 114 IQ healthcare, PO Box 9101, 6500 HB Nijmegen, The Netherlands. Email: j.jacobs@iq.umen.nl. 


\section{Cost/conditions of use}

Permission should be obtained from the authors.

\section{St George's respiratory disease questionnaire (SGRQ)}

The most widely used quality-of-life instrument in the literature especially the "symptoms" domain that can be used alone. Compares to the AQ20 and CRQ. A gold standard but long, not simple enough for daily use. It takes $8-10$ minutes to be completed. Scores are calculated for three domains: symptoms, activity and impact (psychosocial), and also for total score.

Telephone or self-administered. Sensitive to changes in the patient's condition. Many translations. Not COPD specific. Scores range from 0 to 100 , with higher scores indicating poor health.

Where you can get this tool (and the spreadsheet needed to calculate the score)

Professor Paul Jones, Professor of Respiratory Medicine, Division of Physiological Medicine, St George's Hospital
Medical School, London SW17 0RE, United Kingdom Email: pjones@sghms.ac.uk. See also: Yvonne Forde, Academic Secretary, Cardiac and Vascular Sciences, St George's University of London. Email: yforde@sgul.ac.uk. For direct access, visit: http://www.healthstatus.sgul.ac.uk.

\section{Cost/conditions of use}

No cost for use. Copyrighted, permission required. For more information, see American Thoracic Society at: http://qol. thoracic.org/sections/instruments/pt/pages/george.html.

Licensed under Creative Commons Attribution-No Derivative Works Licence. http://creativecommons.org/ licenses/by-nd/3.0/.

\section{Publish your work in this journal}

The International Journal of COPD is an international, peer-reviewed journal of therapeutics and pharmacology focusing on concise rapid reporting of clinical studies and reviews in COPD. Special focus is given to the pathophysiological processes underlying the disease, intervention programs, patient focused education, and self management protocols.
This journal is indexed on PubMed Central, MedLine and CAS. The manuscript management system is completely online and includes a very quick and fair peer-review system, which is all easy to use. Visit http://www.dovepress.com/testimonials.php to read real quotes from published authors. 